\title{
A percepção do timbre em Farben 0 p. 16 n. 3 de Schoenberg: uma abordagem estética e psicoacústica
}

\author{
DANILO ROSSETTI \\ UNICAMP (danilo.rossetti@nics.unicamp.br)
}

\section{Introdução}

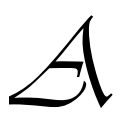

terceira das Cinco Peças para Orquestra Op. 16 (1909) de Arnold Schoenberg (1874 - 1951), intitulada Farben é uma importante obra da música ocidental, do período entre o fim do século XIX e início do século XX. Ela está situada dentro da estética expressionista, e seu grande interesse provém de um acorde a cinco vozes que é sustentado inicialmente por três compassos, e orquestrado de diversas maneiras. Sequencialmente, este acorde sofre modificações harmônicas através de movimentações cromáticas de suas vozes, assim como mudanças de orquestração. Por estas e outras razões, Farben anteriormente já foi objeto de algumas análises conhecidas (FÖRTIG, 1969; RUFER, 1969; DALHHAUS, 1970; BURKHART, 1973; LEÃO MAIA, 2013a, 2013b) que abordam as questões apontadas acima, como também a implementação pelo compositor da ideia de melodia de timbres (Klangfarbenmelodie).

Sobre a importância do timbre, nas páginas finais de sua obra Harmonia (1911), Schoenberg afirmou que o futuro da composição musical passaria por uma investigação mais aprofundada sobre este parâmetro sonoro. Segundo ele, até então, a música tinha dado uma importância maior ao parâmetro das alturas e ao caminho harmônico resultante da sobreposição das vozes. Neste sentido, uma das saídas que o compositor aponta para uma invenção composicional ligada ao timbre seria a possibilidade da utilização da melodia de timbres. Abaixo reproduzimos um trecho de Harmonia, em que Schoenberg se posiciona neste sentido:

A valorização da sonoridade tímbrica, da segunda dimensão do som, encontra-se, portanto, em um estágio ainda muito mais ermo e desordenado do que a valorização estética das harmonias nomeadas por último [...] 0 timbre é, portanto, o 
grande território, e a altura, um distrito. A altura não é senão o timbre medido em uma direção. Se é possível, com timbres diferenciados pela altura, fazer com que se originem formas que chamamos de melodias, sucessões cujo conjunto suscita um efeito semelhante a um pensamento, então há de também ser possível, a partir dos timbres outra dimensão - aquilo que sem mais nem menos denomina-se timbre -, produzir semelhantes sucessões, cuja relação entre si atue com uma espécie de lógica totalmente equivalente àquela que nos satisfaz na melodia de alturas (SCHOENBERG, 2001 [1913], p. 578).

Cramer (2002), referindo-se a este recurso imaginado por Schoenberg, afirma que a melodia de timbres foi uma ferramenta de organização composicional adotada por este compositor principalmente em sua fase conhecida como "atonal" (1908-1913), período em que já havia abandonado o discurso tonal pós-romântico de suas primeiras obras, porém ainda não havia atingido a concepção organizativa do dodecafonismo ou serialismo das alturas - técnica que foi implementada de fato apenas em 1922. Citando Dahlhaus (1970), Cramer ainda afirma que a variação da instrumentação é um elemento essencial da Klangfarbenmelodie, porém não o único. A progressão harmônica também seria outro elemento organizador indissociável deste conceito, confirmada pelo próprio Schoenberg, em 1951: "Klangfarbenmelodien seriam progressões de cores tonais igualando progressões harmônicas em termos de lógica interna" (SCHOENBERG [1951] apud SCHOENBERG, 1975, p. 485, tradução nossa) ${ }^{1}$. Neste mesmo ano, em carta a Josef Rufer, o compositor asseverou ainda que, como característica, a melodia de timbres não envolveria a sucessão de sons individuais tal como um princípio polifônico, mas sim a combinação de "vozes que se movimentam" (SCHOENBERG [1951] apud RUFER, 1969, p. 367).

Apesar destas diferentes análises apontarem a existência de uma melodia de timbres em Farben, esta

1 "Klangfarbenmelodien would be progressions of tone-colors equaling harmonic equaling harmonic progressions in terms of inner logic" (SCHOENBERG [1951] apud SCHOENBERG, 1975, p. 485). 
afirmação não é um consenso. Doflein (1969), afirma que a ideia da melodia de timbres nesta peça seria um mito. Sabe-se que qualquer instrumento musical possui diferentes timbres ao longo da sua tessitura, do grave ao agudo. Neste sentido, qualquer melodia que atravesse diferentes regiões de um instrumento também é uma melodia de timbres, e Schoenberg obviamente tinha conhecimento disso. Doflein afirma que as pequenas movimentações das vozes em semitons cromáticos não são uma melodia. Assevera também que quando todas as cinco vozes se movimentam em uma mesma direção e em um mesmo intervalo (transposição do acorde), não ouvimos o mesmo som com uma orquestração diferente, mas uma mudança de harmonia (DOFLEIN, 1969, p. 204).

Neste artigo, partiremos do pressuposto de que há uma melodia de timbres em Farben. Para isso, nos baseamos na definição de Klangfarbenmelodie fundamentada em depoimentos do próprio compositor e em análises anteriores 294 da obra, as quais consideram, como colocamos anteriormente, que este conceito abrange tanto critérios de variação de orquestração como de variação harmônica. Procuraremos investigar de que maneira o manejo destes parâmetros por parte do compositor afetam a percepção do timbre pelo ouvinte. Inicialmente, buscaremos a origem e as ideias que proporcionaram o surgimento da Klangfarbenmelodie, logo após apresentaremos um panorama de como Schoenberg trabalhou as variações harmônicas desta peça em termos de transposições e movimentação das vozes, apresentando uma redução para piano das vozes principais orquestradas pelo compositor.

Além dos elementos causais enumerados acima (orquestração e harmonia) que definem o timbre e seu espectro sonoro, procuraremos analisar a hipótese do timbre a partir do viés perceptivo, ou seja, como o ouvinte o percebe sonoramente durante a execução da obra. Esta análise estará baseada em elementos perceptivos do som - que resultarão em aspectos de sua qualidade psicoacústica - considerando a ideia de que as seguintes propriedades do som (entre outras) influenciam na percepção do timbre: altura, intensidade, distribuição espectral e sua evolução temporal. Também 
adotaremos o modelo de representação do som teorizado por Helmholtz: uma frequência fundamental mais grave e parciais harmônicos mais agudos, que se sustentam no tempo de maneira estável. Nesse percurso utilizaremos descritores de áudio tais como o croma (que define a qualidade tonal dos agregados tímbricos, excluindo as alturas, em oitavas), centroide (que define o centro de massa, o baricentro do espectro sonoro), loudness (que analisa a percepção da intensidade levando em conta a distribuição de frequências de determinado som), sharpness (descritor ligado à percepção de rugosidade do espectro sonoro) e inarmonicidade (que analisa o quanto a harmonia resultante de determinado som se assemelha, ou não, à distribuição dos parciais de acordo com a série harmônica).

\section{A ideia de Klangfarbenmelodie}

Cor e som [...] São como dois rios que têm sua fonte em uma e na mesma montanha, mas subsequentemente perseguem seu caminho sob condições totalmente diferentes em duas regiões totalmente diferentes, de modo que ao longo de todo o percurso de ambos nenhum ponto entre eles pode ser comparado. Ambos são universais, efeitos elementares agindo de acordo com uma lei universal de separação e tendência à união, ondulação e oscilação, ainda que agindo desta maneira em domínios totalmente diferentes, em diferentes modos, em meios elementares diferentes, para diferentes sentidos² (GOETHE, 1840, pp. 298-9, tradução nossa).

\footnotetext{
2 Color and sound [...] They are like two rivers which have their source in one and the same mountain, but subsequently pursue their way under totally different conditions in two totally different regions, so that throughout the whole course of both no two points can be compared. Both are general, elementary effects acting according to the general law of separation and tendency to union, undulation and oscillation, yet acting thus in wholly different provinces, in different modes, on different elementary mediums, for different senses (GOETHE, 1840, pp. 298-9).
} 
$\mathrm{Na}$ introdução do trabalho, apresentamos o interesse de Schoenberg em trabalhar sobre o parâmetro tímbrico do som. Também colocamos sua definição sobre a melodia de timbres, além de afirmar que, na sua realização, este procedimento envolve o manejo tanto de parâmetros harmônicos quanto de parâmetros de orquestração. Neste item, propomos uma investigação das motivações que levaram Schoenberg a desenvolver esta técnica de escrita musical.

\subsection{Helmholtz: relação entre cores e sons}

É sabido que o físico alemão Herman von Helmholtz (1821-1894) realizou, durante o século XIX, experimentos fundamentais sobre acústica e mecanismos da percepção do som. Sua obra On the sensations of the tone (1954 [1875]) é, até os dias de hoje, uma obra importante neste assunto. Quando falamos de timbre, é comum o definimos como a "cor do som". Mais ainda, em língua alemã, a tradução da palavra timbre é Klangfarbe, ou seja, literalmente a "cor do som". Helmholtz, quando se refere à percepção do timbre (Klangfarbe) em seus trabalhos, faz constantemente alusões à percepção das cores.

Certamente, no início do século XX, Schoenberg tinha conhecimento das obras e das experiências acústicas de Helmholtz, tanto que encontramos referências feitas por Schoenberg ao físico alemão em seu Tratado de Harmonia (2001 [1913]). Investigando a questão do timbre em obras de Helmholtz, encontramos algumas relações entre timbre e cor. Em On the sensations of the tone, por exemplo, ele afirma que a formação do som composto, a partir de diversos parciais, é similar à composição da luz branca proveniente do sol, a partir das diferentes cores do arco-íris (1954 [1875], p. 48). Em outro trecho (HELMHOLTZ, 1954 [1875], p. 64), referindo-se à Richard Waller (Philosophical Transactions, 1686) - obra em que se propôs a redução de todas as cores à mistura de três cores fundamentais (vermelho, azul e verde) - afirma que o fenômeno da mistura de cores apresenta uma considerável analogia àqueles dos tons musicais compostos, no caso da decomposição das cores em três cores fundamentais. 
No entanto, é em Treatise on Physiological Optics Vol. II (1924 [1911]) que Helmholtz propõe uma relação muito mais estreita entre cores e sons. Assevera que "as diferentes sensações das cores nos olhos dependem da frequência das ondas luminosas, da mesma maneira que as sensações das alturas no ouvido dependem da frequência das ondas dos sons"3 (1924 [1911], p. 76, tradução nossa). Também afirma que as recentes descobertas e medições científicas supõem que o espectro de luz como conhecemos é dividido pelo mesmo princípio da escala musical utilizando o número de vibrações das ondas etéreas (HELMHOLTZ, 1924 [1911], p. 76). Helmholtz apresenta também uma "escala de cores", e a relaciona com a escala musical cromática (Tab. 1).

$\mathrm{Na}$ escala de alturas musicais, o Dó (amarelo) corresponde ao Dó central (Dó 4). Na escala de cores, nota-se que os dois extremos do espectro de cores permanecem os mesmos por alguns intervalos cromáticos. Segundo Helmholtz, isto acontece porque na região central deste espectro, o olho tem muito mais habilidade para reconhecer frequências vibratórias do que nas regiões extremas, além de haver diferenças entre a graduação de intervalos de cores e intervalos de alturas sonoras em relação às frequências vibracionais ${ }^{4}$ (HELMHOLTZ, 1924 [1911], p. 76).

\begin{tabular}{|l|l|l|l|}
\hline Fá\# & Fim do vermelho & Ré\# & Azul ciano \\
\hline Sol & Vermelho & Mi & Azul índigo \\
\hline Sol\# & Vermelho & Fá & Violeta \\
\hline Lá & Vermelho & Fá\# & Violeta \\
\hline
\end{tabular}

3 The different sensations of color in the eye depend on the frequency of the waves of light in the same way as sensations of pitch in the ear depend on the frequency of the waves of sound" (HELMHOLTZ, 1924, p. 76).

${ }^{4}$ Convém ressaltar que o estabelecimento de uma analogia operatória entre os fenômenos luminosos e sonoros já havia sido proposta por Augustin-Jean Fresnel em sua obra Théorie de la lumière (1815). 
A percepção do timbre em Farben Op. 16 n. 3 de Schoenberg: uma abordagem estética e psicoacústica

\begin{tabular}{|l|l|l|l|}
\hline Lá\# & Vermelho alaranjado & Sol & Ultravioleta \\
\hline Si & Laranja & Sol\# & Ultra-violeta \\
\hline Dó 4 & Amarelo & Lá & Ultra-violeta \\
\hline Dó\# & Verde & Lá\# & Ultra-violeta \\
\hline Ré & Azul esverdeado & Si & Ultra-violeta \\
\hline
\end{tabular}

Tabela 1: Escala cromática de cores em analogia à escala cromática de sons. (HELMHOLTZ, 1924, p. 77).

\subsection{Percepção da altura por fusão de parciais e fusão de timbres}

No século XIX, algumas décadas antes de Helmholtz publicar seus trabalhos sobre acústica e psicoacústica, August Seebeck descreveu experimentos realizados com uma sirene nos quais quando a frequência fundamental deste som é 298 retirada, ainda continua-se a perceber este som como possuindo a mesma altura, fenômeno que ficou conhecido como altura periódica (periodicity pitch) (SEEBECK, 1841, 1843). A partir desta observação, Seebeck concluiu que não é apenas a frequência fundamental o fator determinante da altura de um som, mas também a forma como seus parciais superiores são distribuídos. Os parciais superiores se fundem com a frequência fundamental devido à periodicidade de suas oscilações, sendo percebidas como uma única estrutura.

No século XX, Jan Frederik Schouten (1940) retomou e confirmou as conclusões de Seebeck a respeito da altura periódica, com o intuito de formular a sua Teoria da Altura Residual (Residue Theory of Pitch). Para Schouten, a Lei de Ohm - teoria empregada por Helmholtz para explicar a percepção das alturas pelo sistema auditivo -, a qual afirma que o ouvido humano decompõe um som musical (que se organiza a partir de uma frequência fundamental com inúmeros parciais sobrepostos) em ondas senoidais simples, é somente válida para os parciais mais graves de um som com oscilações periódicas. Os parciais mais agudos são percebidos em conjunto, por fusão, tal como um amálgama, numa estrutura denominada resíduo, cuja altura percebida é igual à frequência fundamental. Desta feita, para os sons ricos em parciais, o 
ouvido não realiza nenhuma análise espectral do som para que suas qualidades sejam reveladas, mas o percebe através do fenômeno de fusão de seus parciais. Apenas uma minoria dos parciais é percebida separadamente.

Werner Meyer-Eppler (2009, [1954]) definiu a tripla qualidade relativa à percepção da altura sonora. A primeira qualidade é a altura absoluta de um som, que corresponde a uma frequência; a segunda qualidade é o croma, a distribuição das alturas (em semitons, quartos de tom ou outro tipo de distribuição) que se repete de maneira cíclica no interior de cada oitava (até por volta de $4.500 \mathrm{~Hz}$ ); a terceira qualidade seria a altura residual. Meyer-Eppler ainda detectou a existência de um outro fenômeno relativo à percepção da altura, denominado altura formântica (formant pitch). Quando se realiza um experimento para a detecção da altura residual de um determinado som, ao interrompermos a execução da nota sem sua frequência fundamental por aproximadamente um segundo, quando esta volta a soar a sua percepção é totalmente alterada. Ao invés da altura residual, ouve-se um novo som cuja altura está ligada aos parciais remanescentes com maior intensidade; esta nova estrutura é a altura formântica.

Terhardt (1974) definiu as categorias de altura espectral (spectral pitch) e altura virtual (virtual pitch). A altura de um som puro (oscilação simples) seria uma altura espectral. A altura de um som complexo (formado por muitos parciais) seria uma altura virtual. Em relação a estas categorias existem dois modos de percepção: modo analítico (analytic mode), resultando numa altura espectral, e o modo sintético (synthetic mode), resultando na altura virtual. A altura virtual é considerada um atributo de uma percepção auditiva baseada na Teoria da Forma (Gestalt) bem como no fenômeno da altura residual, devido ao fato de que um "contorno" pode ser percebido mesmo quando ele não está presente (tal como o caso da eliminação da frequência fundamental).

Sobre a fusão de diferentes timbres, McAdams (1984), além de Dubnov, Tishby e Cohen (1997), afirmam que os instrumentos musicais emitem sons que nunca são totalmente 
periódicos. Estas aperiodicidades, detectadas numa escala temporal abaixo dos 100 milissegundos, são geradas pelo próprio mecanismo de produção sonora dos instrumentos e são impossíveis de serem controladas pelos instrumentistas. São justamente estas aperiodicidades ou flutuações denominadas jitter - que ocorrem na parte estável dos sons (no seu regime de sustentação) que promovem a fusão de diferentes estruturas num único timbre. 0 timbre, por sua vez, é definido como um fenômeno de estrutura acústica complexa que é apreendido pelo ouvinte como uma única estrutura. Sua diferenciação em relação à textura se dá no sentido em que quando sobrepomos duas texturas diferentes, elas são percebidas separadamente como dois eventos enquanto que um timbre é percebido como uma única estrutura. No nosso entendimento, em Farben ocorre a fusão de diferentes timbres produzidos pelos instrumentos utilizados por Schoenberg na orquestração da obra. Esses instrumentos se fundem numa 300 única estrutura que se modula no tempo de maneira contínua.

\subsection{Schoenberg: pintor e compositor}

Schoenberg, além de compositor era pintor. Seu período mais produtivo nesta atividade foi justamente entre 1906 e 1912, período que corresponde à sua fase composicional "atonal". Segundo Shawn (2003, p. 61), neste período Schoenberg estava constantemente pensando em associações entre sons e cores. No drama musical Die glückliche Hand Op. 18, por exemplo, encontramos na partitura anotações sobre a exata progressão de mudança de cores imaginada por Schoenberg, que acompanha um interlúdio orquestral (SCHOENBERG, 1917, p. 23-24) ${ }^{5}$. Em Farben, por sua vez, o

${ }^{5}$ A cena acontece numa paisagem rochosa (cinza escuro) com alguns pinheiros (com folhas prateadas) perto de um desfiladeiro. Há também duas cavernas que estão temporariamente cobertas por um pano violeta-escuro. No texto que acompanha a partitura, Schoenberg afirma que a montagem não deve ser a imitação de uma paisagem natural, mas uma combinação livre de cores e formas (numa tendência clara à abstração visual). Na sequência, surge uma luz verde-cinzenta por trás. Mais tarde as cavernas são iluminadas por uma luz verde- 
impulso pictórico seria praticamente palpável nas explorações pelo timbre, e um paralelo poderia ser traçado com as suas explorações com as cores no campo visual. A seguir, apresentamos reproduções de dois quadros pintados por Schoenberg em 1910.

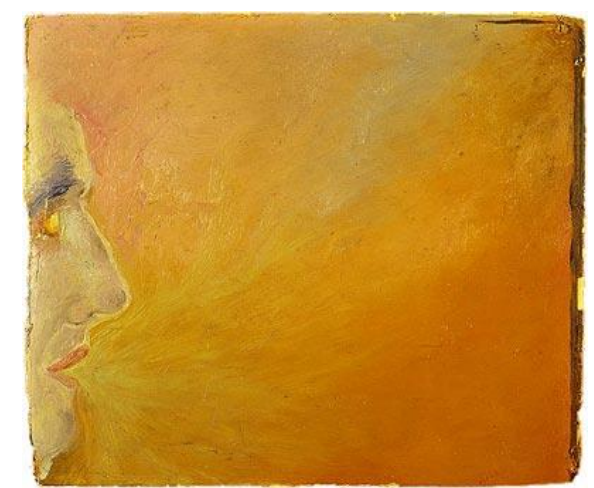

Figura 1.1: Olhar azul [Blauer Blick]. (SCHOENBERG, 1910).

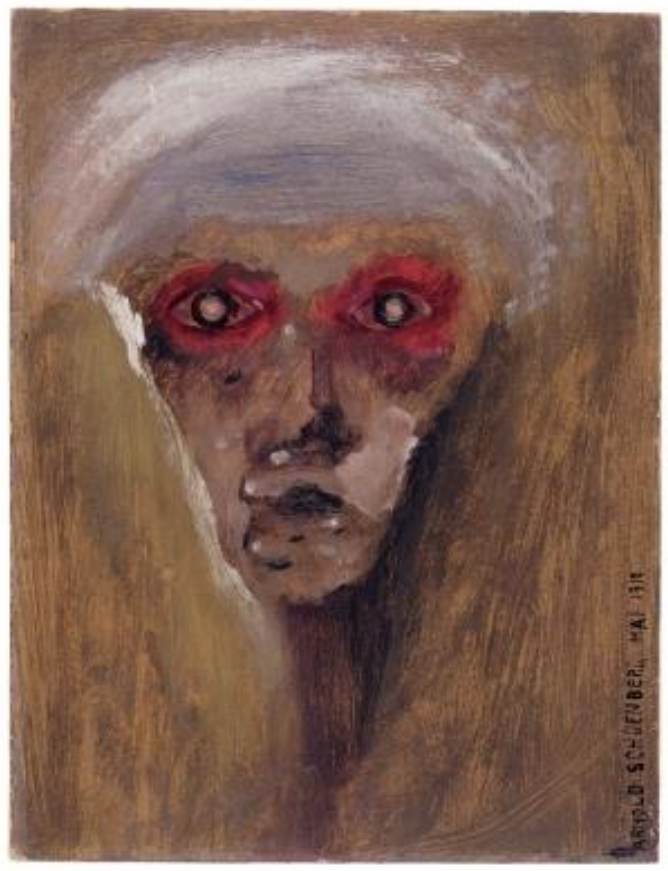

Figura 1.2: Olhar [Blick]. (SCHOENBERG, 1910).

amarelada e, nas rochas, outra violeta-escuro. Quando o homem (personagem principal) aparece entre as duas cavernas, a luz violeta muda gradualmente para o marrom, vermelho, azul, verde e amarelo brilhante (Cf. SCHOENBERG, 1917, p. 23-4). 
Esta associação entre sons e cores que apresentam transformações graduais (do timbre, no caso dos sons) é associada também à transformações psicológicas no receptor, aquele que ouve a música ou vê os quadros. Fundamentandonos em Henri Bergson (1859-1941), principalmente na sua teoria sobre a multiplicidade de estados da consciência (BERGSON, 1988 [1889]), mas também na sua ideia de percepção como seleção de imagens para uma representação (BERGSON, 2010 [1896]), imaginamos que estas transições graduais do objeto percebido são factualmente inextensivas, já que os timbres ou as cores fundem-se na medida em que se transformam, não havendo um limite fixo que determina onde começa ou termina um som, onde começa ou termina uma cor. Os fenômenos da consciência neste contexto não se justapõem; eles possuem uma certa duração e se interpenetram. Ademais, na medida em que se fundem, estes estados psicológicos não mais se dividem, não configurando um fenômeno espacial.

302 As percepções em nossa consciência fundem-se numa continuidade aparente, através de uma modulação entre a imagem da matéria percebida e outras imagens anteriores relacionadas a esta, armazenadas na memória. Este processo de modulação é similar ao processo que ocorre em nossa visão: duas imagens distintas (duas retinas) se fundem numa percepção única (BERGSON, 2010 [1896], p. 64). Neste sentido, as transições de timbre e de cor implementadas por Schoenberg são claramente qualitativas e não segmentáveis enquanto objeto percebido, sendo apreendidas por nossos sentidos como um objeto único. Se pudermos estabelecer paralelos, teríamos, no campo sonoro, a Klangfarbenmelodie (transformação gradual do timbre), no campo visual, a transformação gradual das cores (tal como vimos nos quadros de Schoenberg) e, no campo perceptivo, transformações graduais de estados psicológicos de consciência, que se fundem em constante mudança.

\section{Análise da Partitura}

Para nossas observações a respeito da melodia de timbres implementada por Schoenberg, consideraremos as 
cinco vozes principais orquestradas e trabalhadas harmonicamente pelo compositor de acordo com as análises de Förtig (1969) e Burkhart (1972). Schoenberg utilizou um acorde base, a cinco vozes, condutor da melodia de timbres, que sofre variações harmônicas e orquestrais ao longo da peça. Além dele, em momentos esporádicos encontramos outros acordes formados por sobreposições de intervalos de quartas e quintas justas, além de outros efeitos, como arpejos executados pela harpa, celesta, flauta e alguns outros instrumentos. Nossa análise harmônica não abordará estes últimos elementos citados. Apresentamos a partitura do início de Farben (Fig. 2.2) e a redução de seu acorde inicial a cinco vozes (Fig. 2.1):

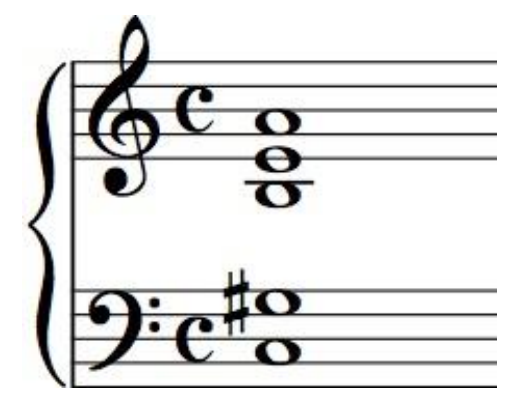

Figura 2.1: Redução do acorde inicial de "Farben" a cinco vozes. 
A percepção do timbre em Farben Op. 16 n. 3 de Schoenberg: uma abordagem estética e psicoacústica
III.

Farben.

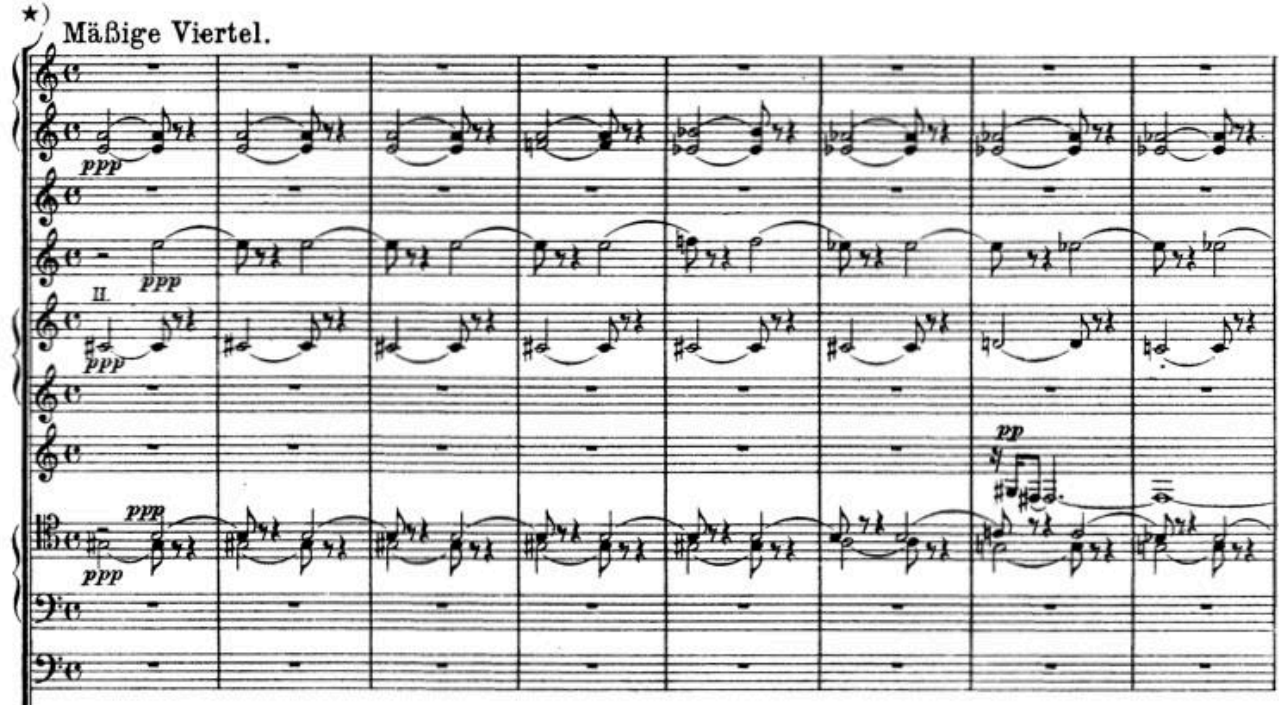

2 kleine Fläten

2 große Flöten

3 Oboen.

Englisch Horn

I. II in $\mathrm{B}$.

3 Klarinetten.

III in D.

BaBklarinette

in $\mathbf{B}$.

I. II.

3 Fagotte.

III.

Kontrafagott.

I. II.

4 Hörner in F.

III. IV.

i. II.

3 Trompeten in B.

III.

I. II.

4 Posaunen.

III. IV.

BaBtuba.

Harfe.

III. mit Dämpfe
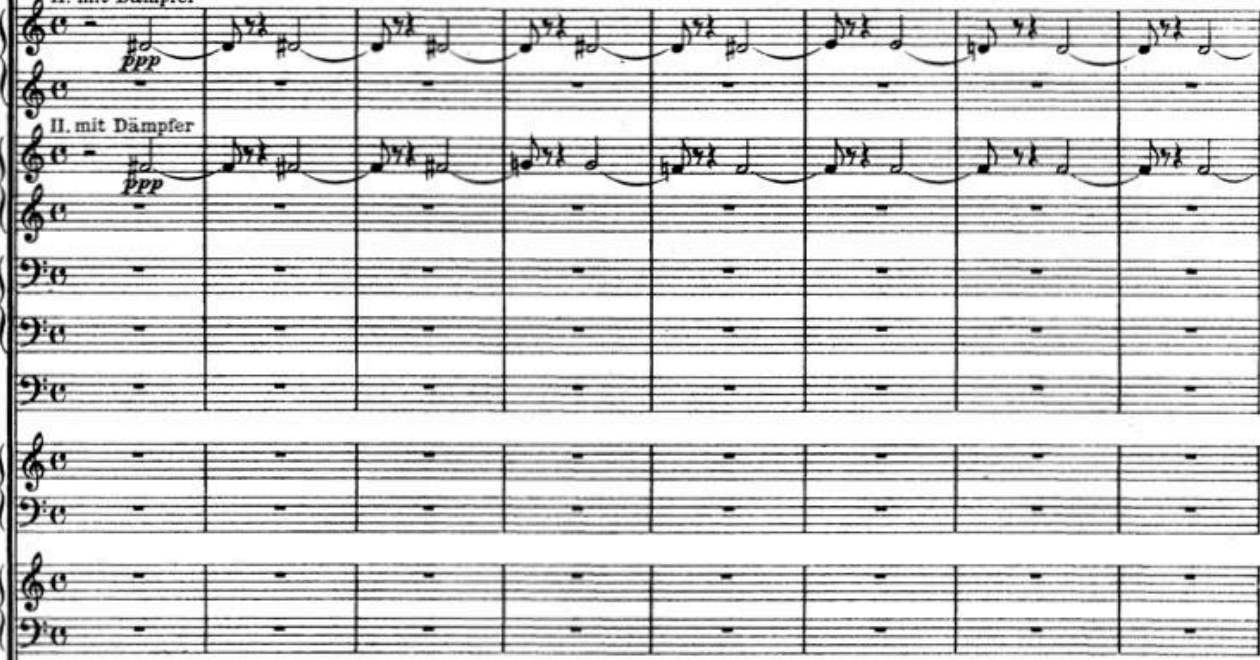

Celesta.

I.

Violinen.

II.

Viola.

Violoncell.

Kontrabaß.

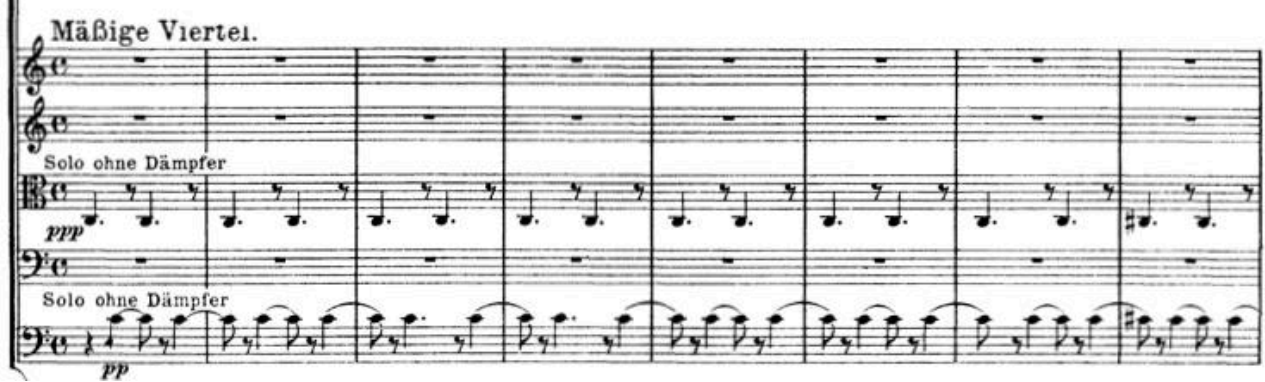

Figura 2.2: Partitura de Farben, compassos. 1 a 8 (SCHOENBERG,

1922, p. 31).

Sobre este acorde (Fig. 2.1), Schoenberg desenvolverá variações harmônicas através de movimentação cromática das vozes, de maneira independente, além de transposições integrais (considerando as enarmonias) ascendentes e 
descendentes deste acorde, em intervalos de segunda e terça (maiores e menores).

0 acorde inicial (Dó 2, Sol\# 2, Si 2, Mi 3, Lá 3) é mantido pelos quatro primeiros compassos da obra. Em relação às transposições, há uma para nona menor abaixo (Si 0, Sol 1, Si b 1, Mi b 2, Lá b 2) nos compassos 10, 11 e 12. No compasso 13, por exemplo, ele é transposto para uma segunda menor abaixo (Si 2, Sol 2, Si b 2, Mi b 3, Lá b 3); nos compassos 15, 16, 19 e 20, para uma segunda maior acima (Ré 2, Si b 2, Ré b 3, Fá\# 3, Si 3); no compasso 25, para uma terça maior acima (Mi 2, Dó 3, Mi b 3, Lá b 3, Ré b 4); no compasso 28, terceiro tempo, para uma terça menor acima (Mi b 2, Si 2, Ré 3, Sol 3, Dó 4); e no compasso 29, segundo tempo, para uma segunda menor acima (Dó\# 2, Lá 2, Dó 3, Mi 3, Si b 3). Estas transposições são mostradas na Fig. 3.

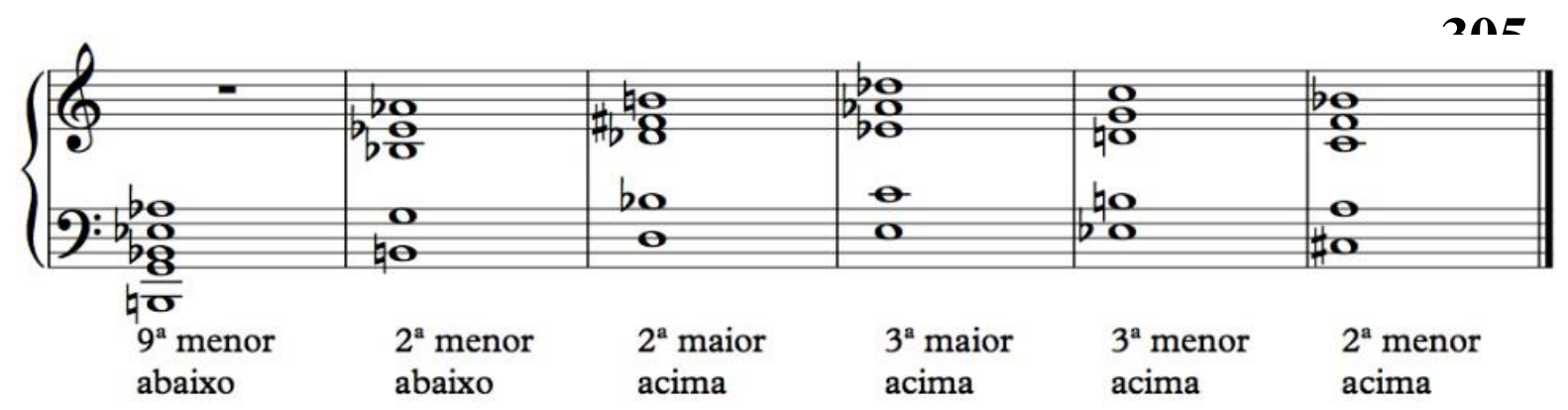

Figura 3: Transposições do acorde inicial de Farben.

Além das transposições integrais do acorde inicial, Schoenberg trabalha também com o movimento independente das vozes, na maioria das vezes um movimento de um único semitom. Estas movimentações podem ocorrer em apenas uma voz ou também em duas ou até três vozes, em movimento direto ou contrário. Este é um ponto importante do trabalho composicional de Schoenberg, ao qual voltaremos na conclusão deste artigo. Quanto ao ritmo de mudanças harmônicas empregado pelo compositor, notamos que este se inicia de forma lenta, assim se mantendo até o compasso 11 (um mesmo acorde permanece por um ou mais compassos). Este ritmo se acelera um pouco entre os compassos 12 e 25, sempre havendo um acorde diferente por compasso (compassos 12 a 21). Entre os compassos 22 e 25 há uma mudança harmônica a cada dois 
tempos (lembramos que o compasso da obra se mantém sempre em 4/4). 0 momento da peça em que há a maior movimentação harmônica ocorre entre os compassos 26 e 29: as vozes se movimentam a cada unidade de tempo, ou mesmo mais de uma vez a cada tempo. Após este trecho em que o ritmo harmônico é mais acelerado, a peça volta a ter seu caráter inicial, com cada acorde tendo um ou mais de um compasso de duração.

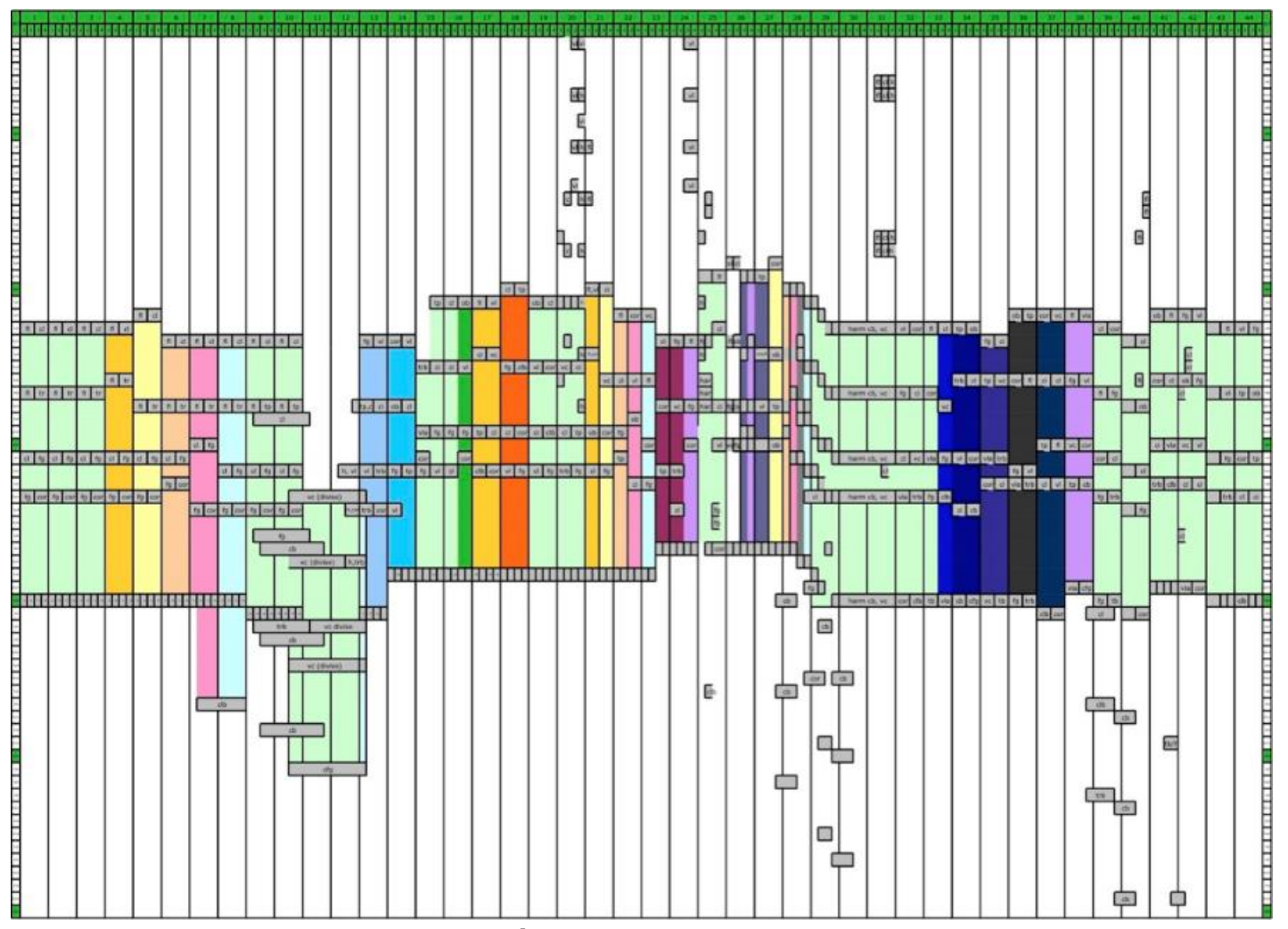

Figura 4: Representação gráfica de Farben (Durações X Alturas).

$\mathrm{Na}$ Fig. 4 propomos uma representação gráfica de Farben em que temos, no eixo $\mathrm{X}$, a duração em compassos e, no eixo $\mathrm{Y}$, as alturas tocadas pelos instrumentos. A localização espacial das alturas das notas tocadas está grafada na cor cinza, considerando uma disposição com as alturas mais graves na parte inferior e alturas mais agudas na parte superior da figura. O espaço harmônico compreendido entre as notas dos acordes está preenchido por uma cor que representa uma determinada harmonia imaginada pelo compositor. Nesta representação, cores iguais significam acordes iguais, ou também transposições destes acordes que conservam o mesmo espaço 
intervalar entre as notas que o compõem. Pode-se perceber que o acorde inicial (em verde claro) é aquele que mais vezes aparece, considerando suas transposições. Alguns outros acordes também acontecem mais de uma vez. Também nota-se que o ritmo de mudança da harmonia (além da orquestração) acelera-se a partir do compasso 13, atingindo a maior velocidade entre os compassos 26 a 29 (região central da Fig. 4). A partir do compasso 30 este ritmo se desacelera e retorna ao andamento do ritmo harmônico inicial, de um novo acorde a cada compasso. As cores do preenchimento foram definidas aleatoriamente. Como veremos a seguir, o âmbito harmônico da distribuição das alturas que fazem parte dos acordes tem influência na qualidade da percepção do timbre.

\section{A percepção da qualidade tonal}

Para a investigação sobre a percepção do timbre em Farben, realizamos primeiramente uma análise a partir do áudio da peça (ZENDER, 1997). Trabalhamos com o programa Sonic Visualiser e, sobre o áudio, aplicamos o descritor NNLS Chroma. O croma nos descreve a percepção psicológica do timbre de um som complexo e nos dá uma representação cíclica da "qualidade tonal" do áudio analisado. Nesta descrição, a altura do som não é considerada (em relação a oitavas), com a sua qualidade tonal, ou seja, sobre quais tons da escala cromática de doze semitons se baseia a percepção de determinado som complexo (MEYER-EPPLER, 1954; SHEPARD, 1964).

Apesar de sabermos pela partitura quais notas estão sendo tocadas pelos instrumentos, o croma nos descreve quais partes do espaço tímbrico (neste caso, os doze sons do total cromático) estão sendo preenchidas em determinado momento. No trecho de 1" a 23", correspondente aos compassos 1 a 3, percebe-se que a percepção tonal situa-se exatamente nas notas correspondentes ao acorde inicial. No entanto, as notas Mi e Lá são percebidas com maior intensidade (tocadas pelas flautas, corne-inglês e trompete). Na Fig. 5, em que vemos este trecho, nota-se que os espaços sonoros entre as 
A percepção do timbre em Farben Op. 16 n. 3 de

Schoenberg: uma abordagem estética e psicoacústica

notas Si e Dó, Sol\# e Lá são ocupados totalmente e se fundem numa percepção única.

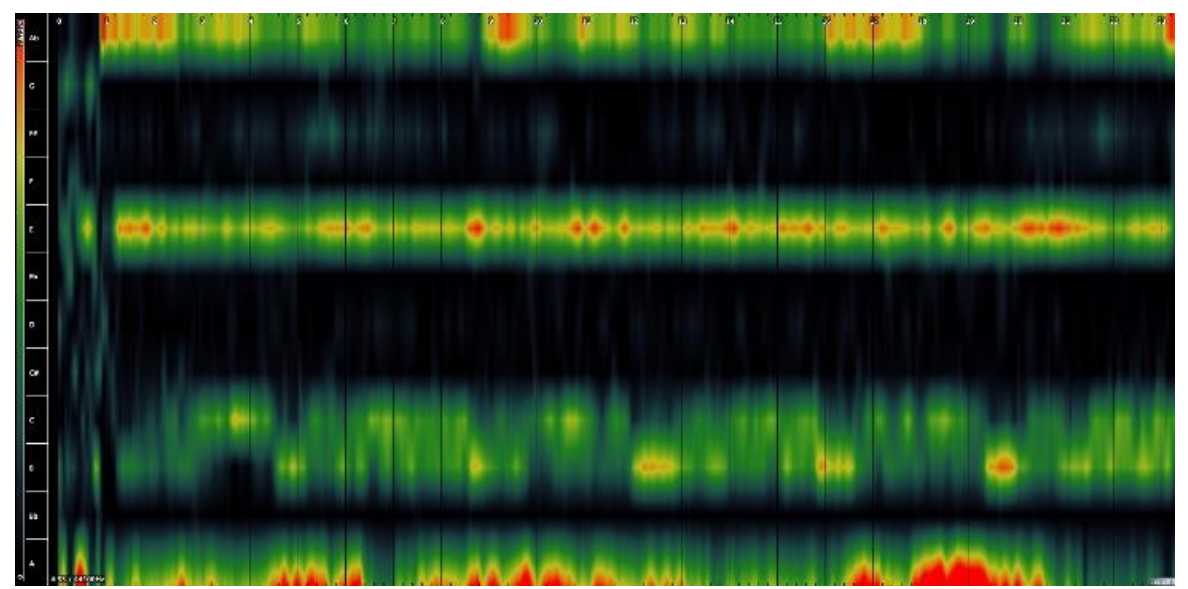

Figura 5: Descritor NNLS Chroma (Sonic Visualiser), trecho entre 1" e 23"

Aplicando este descritor à parte de maior movimentação das vozes, entre os compassos 26 e 29, nota-se que a percepção do timbre é menos tonal e mais difusa. 0 espaço tímbrico é muito mais denso, dificultando a percepção dos tons de maneira isolada. 0 que ocorre é uma percepção localizada de diversas tensões e movimentações sonoras que vêm a se estabilizar nos momentos seguintes.

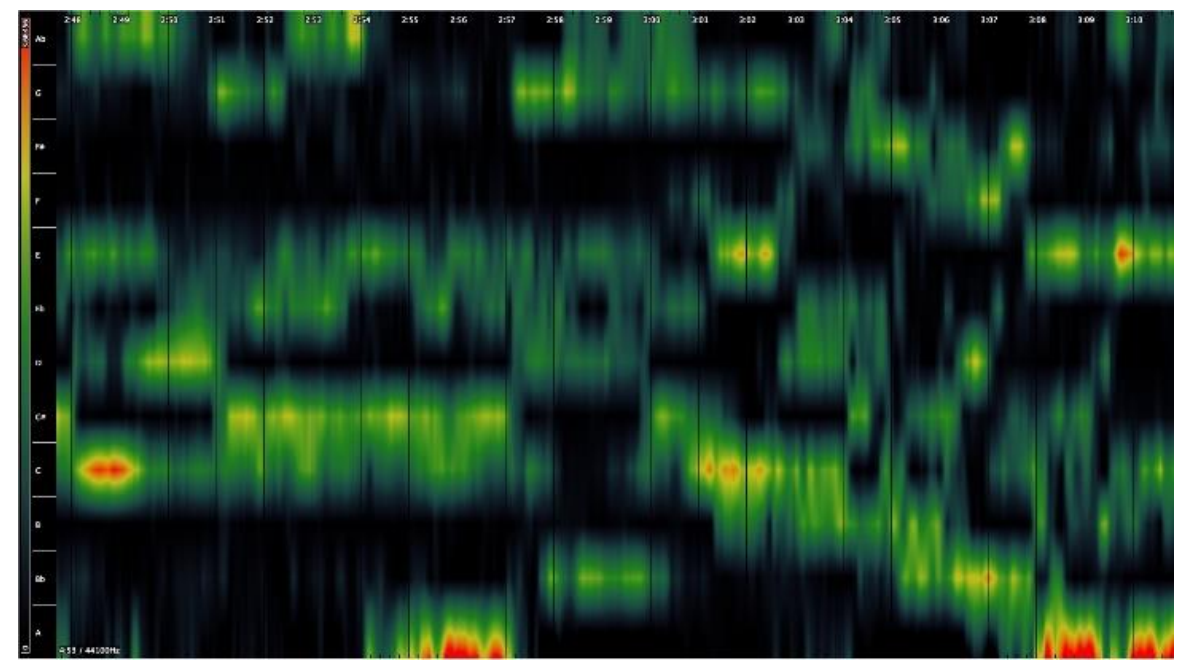

Figura 6: Descritor NNLS Chroma (Sonic Visualiser), trecho entre 2'48' e 3'11'

Ademais destes dois momentos contrastantes apresentados, a percepção da melodia de timbres 
implementada por Schoenberg apresenta ao longo da peça uma certa linearidade. Há sempre alguma tensão embutida nos acordes: no acorde inicial, por exemplo, encontramos dois semitons cromáticos (Sol\# - Lá, Si - Dó). Esta tensão é sempre mantida nos acordes subsequentes (que também apresentam semitons cromáticos em sua formação), de maneira que a movimentação horizontal das vozes sempre tem um caminho resolutivo a percorrer.

Outra informação importante obtida através deste descritor é que, na gravação que utilizamos, no trecho referente ao último compasso da obra - no qual temos na partitura o mesmo acorde inicial (Dó, Sol\#, Si, Mi, Lá) - a percepção da nota Si é praticamente extinta no trecho da fermata final. A resolução Si - Dó é enfatizada pelo fato de que na orquestração temos a nota Dó tocada por quatro instrumentos (clarinete baixo, contra-fagote, viola e contrabaixo) e a nota Si tocada apenas pelo trompete. Temos como resultado a percepção clara de um acorde de Lá menor que pode ser visto como resolução da tensão existente ao longo de toda a obra - ocasionada pela utilização de acordes contendo sempre semitons cromáticos -, apesar de também haver um Sol\# tocado pelo corne-inglês, este sem muita presença (que também pode ser entendido como uma sétima maior do acorde de Lá). Abaixo, apresentamos o trecho correspondente aos dois últimos compassos da peça, em que a harmonia, a partir da informação da partitura, teoricamente deveria permanecer estática. Entre 4'41" e 4'42" há uma clara subida de percepção tonal do Si para o Dó. 
A percepção do timbre em Farben Op. 16 n. 3 de

Schoenberg: uma abordagem estética e psicoacústica

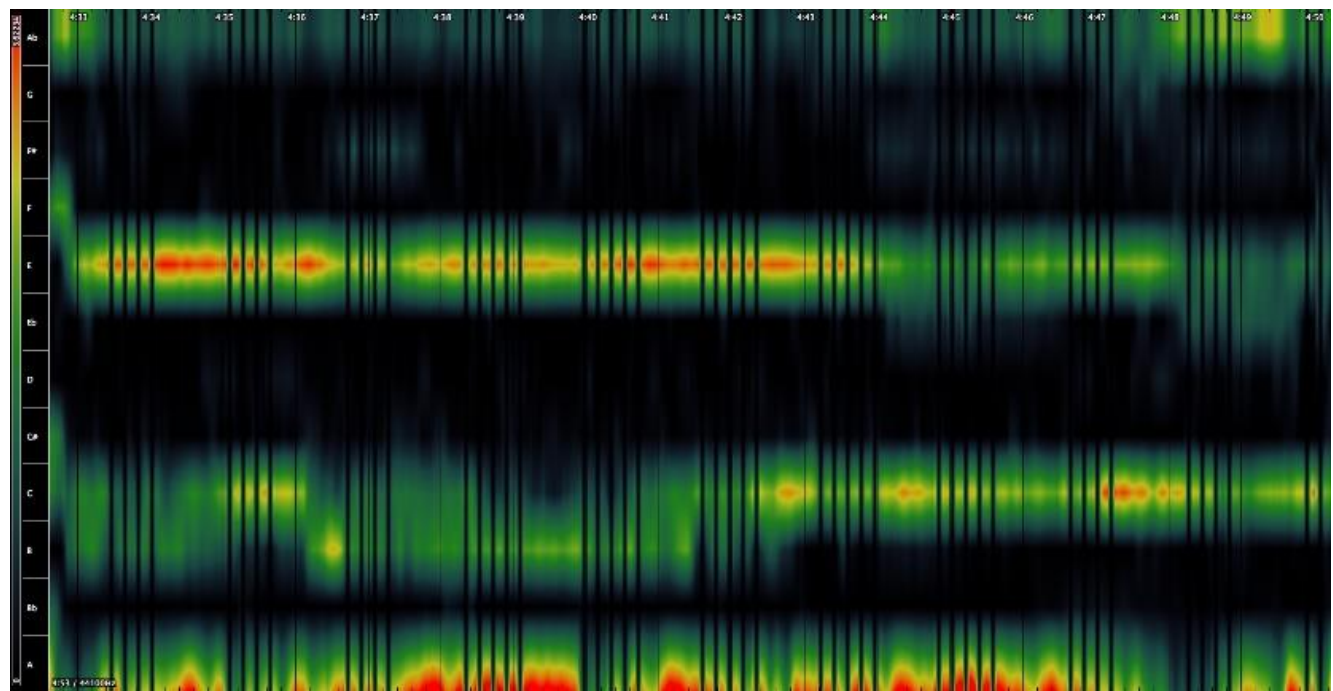

Figura 7: Descritor NNLS Chroma (Sonic Visualiser), trecho entre 4'33"' e 4'50'

\section{Avaliação da percepção do timbre}

0 timbre, elemento sonoro também ligado ao

310 fenômeno perceptivo do som, apresenta uma dificuldade de análise devido à sua complexidade, pois de fato não existe uma grandeza única que explique sua configuração, podendo ser compreendido pelas inter-relações que se estabelecem entre seus componentes. Neste sentido, é importante analisá-lo de acordo com suas diferentes qualidades perceptivas notadas pelo ouvinte. Nesta tarefa, após descrevermos a percepção tonal do timbre, aplicamos ao áudio outros tipos de descritores que evidenciam diferentes elementos que estão relacionados às suas qualidades perceptivas.

Em nossa análise tímbrica ${ }^{6}$ de Farben, decidimos por trabalhar com quatro descritores que nos forneceram gráficos e nos auxiliaram a entender o comportamento qualitativo e as transformações do timbre no tempo. São eles spectral centroid (centroide), sharpness (aspereza), loudness (intensidade) e inharmonicity (inarmonicidade). A seguir, na Fig. 8, apresentamos os quatro gráficos referentes às qualidades acima mencionadas, nos quais é possível visualizar suas características individuais e sua evolução temporal. Acima dos

${ }^{6}$ Agradecemos a Didier Guigue e Mikhail Malt pelo auxílio nesta tarefa. 
gráficos, incluímos as cores que representam a harmonia da peça, tal como na Fig. 4.

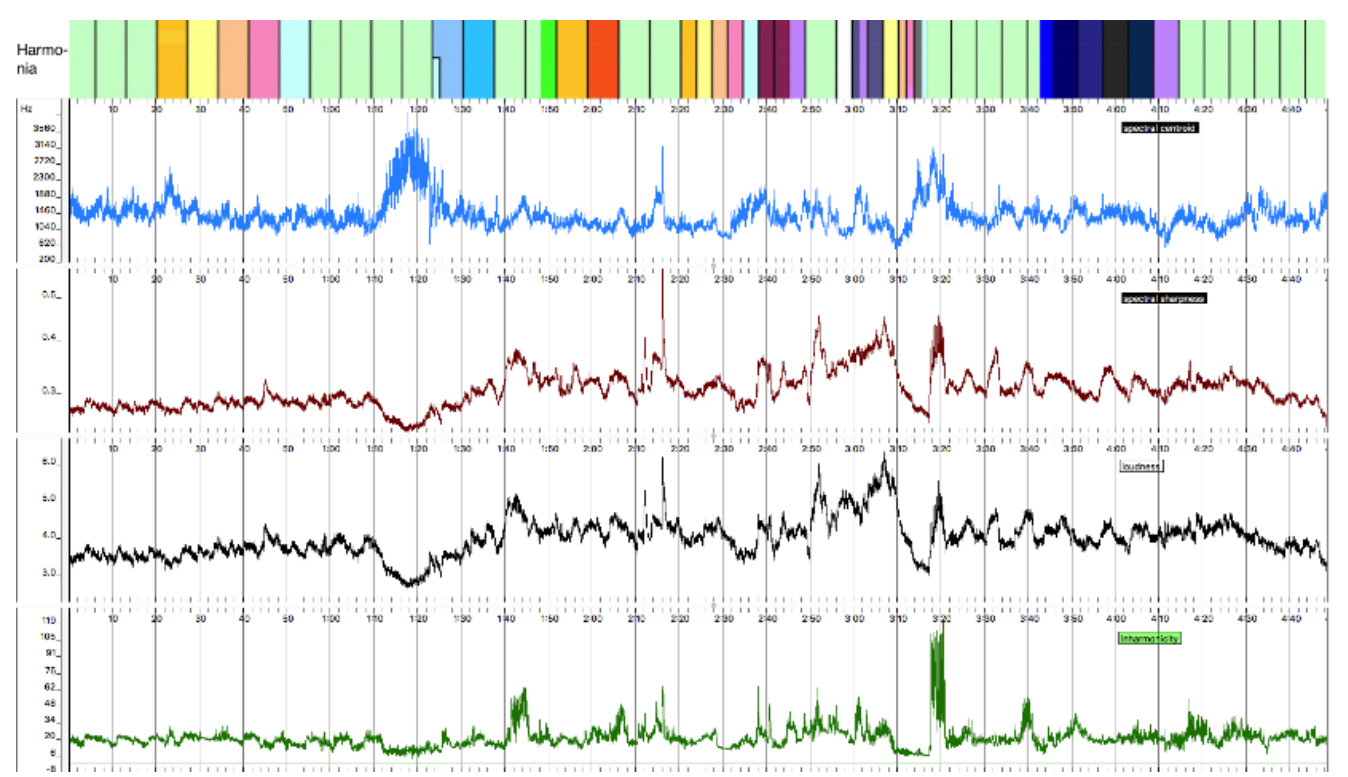

Figura 8: Descritores centroide, sharpness, loudness e inarmonicidade e sua evolução no tempo.

Optamos por estes quatro descritores com o intuito de estabelecer um modelo de análise do timbre para peças instrumentais com essas características, ou seja, aquelas com uma preocupação composicional voltada para transformações contínuas do espectro sonoro, ou seja, com uma preocupação voltada para a percepção estética do timbre. Em relação à Fig. 8 , nota-se que os contornos dos gráficos apresentam algumas características semelhantes, e outras diferentes. Nos próximos parágrafos trataremos de destrinchar individualmente as informações fornecidas por cada descritor.

\subsection{Centroide (Spectral Centroid)}

O centroide é o baricentro do espectro sonoro (PEETERS, 2004, p. 13). É o centro de massa espectral do som, no qual se situa a sensação de brilho do espectro, medido em Hertz. Através de uma análise detalhada das informações deste descritor, pode-se observar as variações do brilho espectral ao longo do tempo, que sofre influência das variações, entre outras, de dinâmica, altura, densidade e orquestração, 
informações estas que são estabelecidas pelo compositor na partitura. Na Fig. 9 apresentamos o gráfico da evolução do centroide em Farben, com indicações de direcionalidade e sentido destas variações, incluindo uma hipótese de segmentação formal da peça.

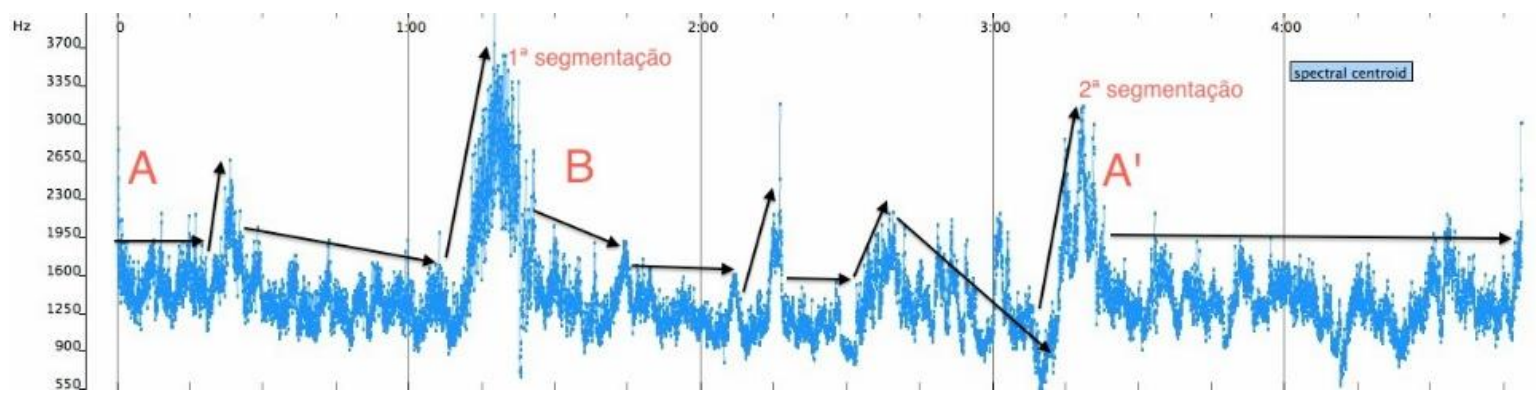

Figura 9: Interpretação do centroide na sua evolução temporal

Numa possível interpretação do gráfico acima, a sensação de brilho do timbre se mantém constante nos primeiros compassos. 0 primeiro pico que observamos (23") 312 refere-se à primeira mudança do acorde inicial (c. 4). A seguir, temos uma nova estabilidade, num leve decrescendo linear, até 1'15". Aqui, temos uma espécie de filtro passa-baixos, em que o acorde inicial é transposto uma nona menor abaixo (c. 10 a 12). É interessante notar que a sensação de brilho do espectro atinge a região de $3.500 \mathrm{~Hz}$, apesar de termos, na partitura, a escrita do acorde inicial transposto mais de uma oitava para o grave. Encaramos este trecho como uma segmentação formal (fim da parte A), que dá início a uma nova ideia.

A parte B que aqui se inicia (1'25", c. 13), apresenta mais variações de brilho espectral, principalmente pelo maior ritmo de variação harmônica e de condução de vozes. Notas agudas das madeiras (oboé, flauta e piccolo, c. 15 e 20, 1'40" e 2'15") geram uma subida na escala de percepção do centroide. Em 2'45" temos o momento de maior densidade da peça, no qual ocorre grande variação da percepção do brilho: há picos mais agudos que descendem (c. 26). Entre 3'02" e 3'15" temos trecho descendente em tremolo das violas e violoncelos, sonoridade que se destaca na massa tímbrica e conduz a percepção do brilho espectral para a região grave (c. 28 e 29). Entre 3'15" e 3'20" temos o retorno ao acorde inicial de Farben, acrescido a duas notas Dó (uma e duas oitavas abaixo 
da nota fundamental do acorde), tocadas pelo fagote e contrafagote (c. 30). Apesar deste pedal grave, a percepção do brilho do timbre novamente é mais aguda, atingindo $3.000 \mathrm{~Hz}$. Definimos este momento como uma nova segmentação formal (fim da parte B), que dará início à reexposição da primeira ideia.

Denominamos este novo trecho A', reexposição da primeira parte. É um momento em que o centroide se encontra mais constante, sem variações significativas. As variações que encontramos referem-se novamente à presença de madeiras no agudo (oboé, 3'40", c. 34), e trechos em que trombone e tuba se destacam, levando esta percepção bastante para o grave (4'12').

\subsection{Aspereza (Spectral Sharpness)}

O segundo gráfico que apresentamos, spectral sharpness, determina a sensação de agudeza ou aspereza na percepção do timbre. Esta sensação está relacionada à densidade espectral, no entanto, no sentido inverso daquilo que conhecemos como agradabilidade (pleasantness). Ela também depende de outras sensações como roughness (presença de batimentos devido a intervalos dissonantes como sétimas, nonas e segundas), loudness e sensação de tonalidade (harmônicos coincidentes) (FASTL; ZWICKER, 2007, p. 239). A medição do sharpness é computada utilizando a escala Bark ${ }^{7}$, uma escala psicoacústica logarítmica proposta pelo próprio Zwicker, em que os valores variam dentro de 24 bandas críticas de audição (valores de 1 a 24). A unidade de medida deste descritor foi denominada acum. Na Fig. 10 apresentamos o gráfico com a evolução do sharpness em Farben, com as indicações de possíveis direcionalidades temporais.

\footnotetext{
${ }^{7}$ As frequências que delimitam as bandas críticas da escala Bark são, em Hertz, 20, 100, 200, 300, 400, 510, 630, 770, 920, 1.080, 1.270, $1.480,1.720,2.000,2.320,2.700,3.150,3.700,4.400,5.300,6.400$, $7.700,9.500,12.000$ e 15.500 .
} 


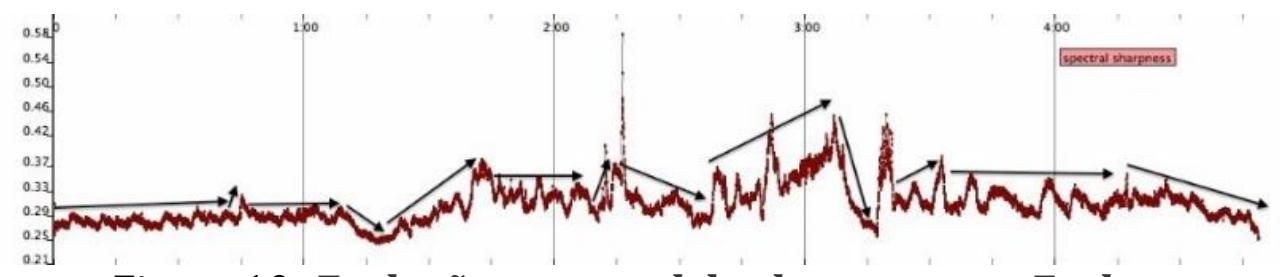

Figura 10: Evolução temporal do sharpness em Farben

Em relação à percepção de aspereza em Farben, ela tem um início constante, com um pequeno pico em 45", decorrente da nota Mi grave entoada pelo clarone (c. 7 e 8). Após este momento, esta qualidade sonora segue constante até 1 '10", local da primeira segmentação formal. No trecho entre 1 '10" e 1'25", em que tivemos uma grande subida dos valores do centroide, observamos um decréscimo nos valores do sharpness. Observamos, portanto, direcionalidades inversas entre centroide e sharpnness nesse ponto.

A parte B, no geral, apresenta uma sensação de aspereza maior do que a parte A. Notas agudas do oboé, flauta, piccolo, harpa e celesta intensificam esta sensação. Ademais, no trecho de maior densidade orquestral (entre 2'38" e 3'07") observamos uma acréscimo significativo na medição desta sensação em relação ao timbre resultante. No segundo momento de segmentação formal (3'10" a 3'17") há novamente uma caída significativa na medição do sharpness.

No trecho da reexposição da parte A, há logo no início dois picos de intensidade do sharpness, ocasionado novamente por notas agudas do piccolo e do oboé, provavelmente devido à sonoridade estridente destes instrumentos no agudo. É importante também notar que, a partir de 4'25" (c. 41), há um decréscimo gradual até o final da peça, numa espécie de resolução no interior do som dos componentes dissonantes do timbre. Na medida em que esta sensação de aspereza vai diminuindo, poderia ser notado um acréscimo na sensação de agradabilidade (pleasantness). 


\subsection{Nível de Sonoridade (Loudness)}

O próximo gráfico que relacionamos aborda a sensação psicoacústica do nível de sonoridade ou volume da obra, também conhecido como loudness. 0 loudness pertence à categoria das sensações de intensidade do som, que é variável em relação às diferentes bandas de frequência. 0 ouvido humano privilegia a escuta das frequências médias, dentro das quais se situam as frequências fundamentais e os harmônicos da fala (entre cerca de 500 e $4.000 \mathrm{~Hz}$ ). Nesta banda de frequências, precisamos de menos intensidade de um som para que este seja percebido com clareza pois, nesta região, nosso ouvido é mais sensível. Por outro lado, em regiões muito graves e muito agudas do espectro frequencial, necessitamos de uma intensidade sonora muito maior para que um determinado som seja percebido com clareza. No universo acústico, o loudness está relacionado ao nível de pressão sonora, porém a sensação perceptiva da intensidade depende também de outros fatores como largura da banda de frequências, densidade do espectro e duração do som. A escala de loudness pode ser medida em phons (medição perceptiva em decibels) ou em sones (um sone equivale à intensidade de um sinal de 40 phons de uma frequência de 1KHz) (Cf. FASTL; ZWICKER, 2004, p. 203-207). $\mathrm{Na}$ Fig. 11 temos a representação gráfica do loudness em Farben, além de uma possível interpretação direcional.

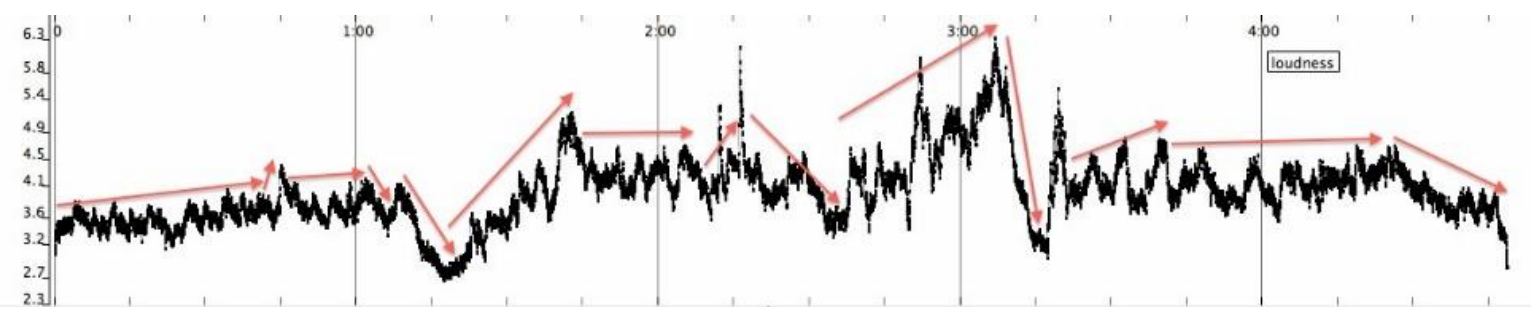

Figura 11: Evolução temporal da sensação de intensidade (loudness)

Em relação às dinâmicas propostas por Schoenberg na partitura, elas estão notadas sempre como pianissíssimo ( $p p p)$, pianíssimo $(p p)$, piano $(p)$ ou mezzo piano $(m p)$, ou seja, o compositor imaginou uma sonoridade geral de pouca intensidade. A diferença da percepção de intensidade entre as partes, tal como podemos notar no gráfico da Fig. 11, ocorre 
principalmente pela maior quantidade de instrumentistas tocando, como também pela presença de notas muito agudas, além de trechos com mais ataques de notas e com alguns efeitos, como tremolo das cordas (c. 28 e 29).

No início da peça (parte A), temos uma sonoridade bastante sutil, que cresce lentamente. $\mathrm{Na}$ primeira segmentação formal, o nível de loudness cai para o menor nível encontrado na peça (acorde em $p p p$ dos violoncelos e contrabaixos na região grave). No início da parte $\mathrm{B}$, temos a intensidade subindo até atingir um pico em 1'40", momento em que temos o ataque da nota Si 3 pelo oboé em $p$ (região bastante sonora do instrumento), em contraste com todos os outros instrumentos que tocam notas em $p p$ ou $p p p$. Nesta parte, até 2'30", temos uma intensidade relativamente constante, com alguns picos representados por ataques de notas agudas do piccolo, harpa e celesta. Neste ponto, temos uma redução de intensidade (c. 23 e 24), que indica um respiro 316 para a grande subida de volume a partir deste ponto até 3'12", momento do tutti orquestral em que o pico de loudness da peça é alcançado; momento mais denso, com mais ataques de notas e efeitos dos instrumentos. Após este trecho, temos um grande vale de intensidade, caracterizado por harmônicos dos violoncelos e contrabaixos, e pedal grave na nota Dó do fagote e contra-fagote. 0 início da reexposição é então apresentado e delimitado pela escrita em oitavas do piccolo na região aguda (Ré 4 e 5, Mi 4 e 5, em tercina de colcheias, c. 31).

A parte $\mathrm{A}^{\prime}$ inicia-se com um novo equilíbrio relativo de intensidade, semelhante ao encontrado no início da parte $\mathrm{B}$, antes do tutti orquestral. Novamente temos alguns picos devido a notas agudas do oboé e corne-inglês (c. 34 a 36). A partir de 4'25" (c. 41), observamos uma curva descendente gradual da intensidade da peça, tal como se fosse um lento fade-out, anunciando que a peça caminha para seu final. Seria um retorno à sonoridade inicial, bastante sutil. Farben se apresenta como um espelho de intensidades: um início em $p p$ que cresce lentamente até o fim da parte A. Na parte B temos logo um crescendo que eleva o nível da intensidade média, nível este que cresce mais ainda no final desta parte, momento de clímax sonoro. A parte $A^{\prime}$ inicia-se com a sonoridade 
comparável à do início da parte $\mathrm{B}$, sonoridade esta que decresce e se esvai na medida em que nos aproximamos do fim da peça, momento em que atingimos um nível de sonoridade próximo daquele inicial.

\subsection{Inarmonicidade}

A descrição da inarmonicidade de um sinal sonoro representa a divergência dos componentes espectrais do sinal em relação a um sinal puramente harmônico (PEETERS, 2004, p. 17). A harmonicidade, qualidade contrária, representaria a convergência do agregado tímbrico em relação aos harmônicos da sua nota fundamental, sempre em referência à representação do som de Helmholtz, uma superposição de parciais harmônicos (que respeitam determinadas proporções) a partir de uma nota fundamental.

Por exemplo, se analisarmos um acorde do Dó maior, formado por tônica, terça e quinta, encontraríamos um grande grau de harmonicidade, já que muitos dos harmônicos das notas Sol e Mi coincidem com os harmônicos da nota fundamental Dó. Por outro lado, se analisarmos um acorde de Dó com algumas notas agregadas, por exemplo uma sétima menor (Si b ) e uma nona aumentada (Ré\#), encontraremos um maior grau de inarmonicidade, já que os harmônicos superiores destas notas serão divergentes dos harmônicos superiores de Dó. A seguir, apresentamos o gráfico que descreve o coeficiente de inarmonicidade em Farben.

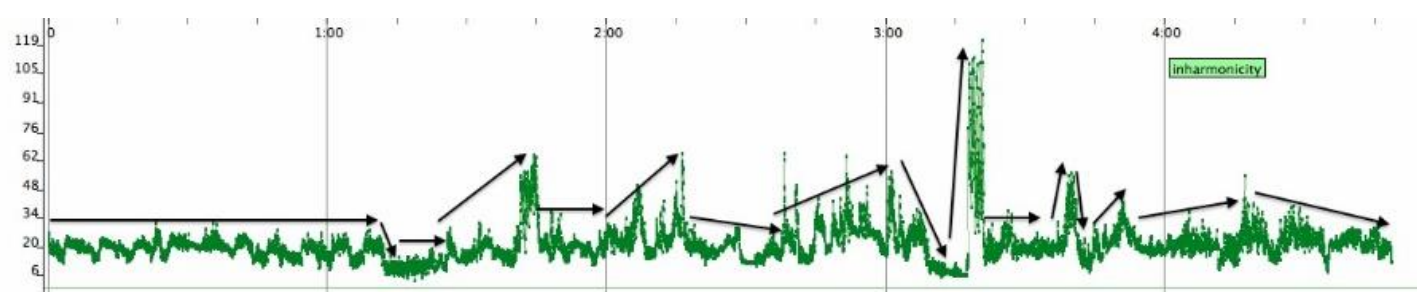

Figura 12: Evolução temporal do grau de inarmonicidade em Farben

Inicialmente, nota-se que a parte A apresenta uma inarmonicidade constante, valor este que decai na zona de transição entre A e B, entre 1'10" e 1'20". A parte B, por sua 
vez, apresenta uma variação muito maior desta característica do timbre. Os maiores valores de inarmonicidade nesta parte são relativos às notas agudas do oboé e piccolo, provavelmente também pelos transientes encontrados no envelope espectral do som destes instrumentos.

Em relação à forma de onda, o som senoidal apresenta uma maior harmonicidade. Na medida em que temos um som instrumental que se afasta destas características e apresenta mais componentes que se assemelham espectralmente ao ruído, temos um aumento do grau de inarmonicidade do sinal. O fim da parte B (c. 26 a 29) soa mais inarmônico, provavelmente pelo aumento da densidade orquestral. Maior quantidade de instrumentos, neste trecho, gera maior quantidade de notas diferentes sendo tocadas e, consequentemente, maior divergência quanto aos harmônicos superiores destas notas.

0 vale de transição entre B e A' é bastante harmônico. Isto é sonoramente claro pois nota-se uma sonoridade bastante límpida neste trecho. É interessante notar, no compasso 32 (3'17" - 3'20") - em que temos ainda sustentados os harmônicos das cordas iniciados no compasso anterior - que este é o momento da peça em que existe maior inarmonicidade. Isto se deve às notas tocadas pelo piccolo em oitavas, numa região bastante aguda. Neste trecho percebe-se claramente um choque de diferentes timbres que não chegam a se fundir, tal como ocorre na grande maioria dos outros momentos da peça (de fato o impulso composicional de Schoenberg nesta obra). 0 ouvido percebe como timbres completamente distintos os harmônicos das cordas e as notas do piccolo.

Comparativamente, as partes $\mathrm{A}^{\prime}$ e A se assemelham bastante quanto à avaliação deste descritor, certamente porque a harmonia destas duas partes é bastante semelhante. Os picos que encontramos novamente se referem a notas agudas do oboé e piccolo. 


\section{Considerações Finais}

A partir dos pontos analisados neste trabalho, apresentamos algumas considerações sobre o processo de composição empregado por Schoenberg em Farben.

1) A ideia de Klangfarbenmelodie como combinação de vozes que se movimentam, assim definida pelo próprio Schoenberg e apresentada na introdução deste trabalho, seria o mecanismo condutor da melodia de timbres em Farben. Para ilustrar este procedimento, se observarmos os compassos 3 a 7 , temos o seguinte: do compasso 3 para o 4, o Mi (segunda voz mais aguda) caminha para o Fá; do compasso 4 para o 5 , as duas vozes mais agudas (Fá - Lá) realizam movimento contrário em direção a Mi b - Si b; entre os compassos 5 e 6, o Si b (nota mais aguda) desce para o Lá b e o Sol\# (segunda nota mais grave) ascende para o Lá; finalmente, entre os compassos 6 e 7, temos o Si (nota intermediária) movimentando-se para o Dó, e o Lá (atingido neste compasso) indo em direção ao Sol.

2) Muitas tentativas com o intuito de relacionar sons e cores já foram realizadas, como, entre outras, a teoria das cores de Goethe e as experiências acústicas e psicoacústicas de Helmholtz. No entanto, em relação à atividade criativa de Schoenberg do início do século XX enquanto compositor e pintor, fica também bastante claro que esta relação estava sendo buscada. Pinturas como as relacionadas nas Fig 1.1 e 1.2 são bastante ilustrativas como exemplos de uma busca por uma transição gradual e contínua de cores, assim como Farben é uma busca - em relação ao som - de uma transição gradual e contínua do timbre. Ademais, esta característica da obra de Schoenberg é restrita a um período específico: os primeiros anos do século XX. As teorias que explicam a percepção da altura por fusão de parciais periódicos e a fusão de diferentes timbres também estão sintonizadas com a percepção do timbre em Farben.

3) A ideia de apresentar um acorde inicial contendo em si dois semitons cromáticos (Sol\# - Lá, Si - Dó) e as movimentações posteriores das vozes, que também formam 
acordes que contêm semitons cromáticos, demonstram o fio condutor do conceito de melodia de timbres nesta obra. No desenrolar da peça, as sensíveis vão sendo resolvidas. Porém, neste processo, novas segundas menores (geradoras de tensão) vão sendo criadas e resolvidas sucessivamente. A resolução final, em que temos a sensação auditiva de um acorde de Lá menor só ocorre, como apresentado, no último compasso da peça.

4) 0 croma, descritor da qualidade tonal do timbre, nos demonstra que nesta peça a melodia de timbres apresenta zonas híbridas de percepção, ou seja, os espaços entre os semitons cromáticos se fundem, provocando uma percepção localizada de aglutinação dos intervalos. Em momentos de maior densidade instrumental e maior movimento harmônico (compassos 26 a 29), a percepção do timbre é mais difusa: a percepção de tons isolados é dificultada devido a um maior preenchimento do espaço tímbrico, tornando-se menos 320 localizada em pontos de tensão (semitons cromáticos) e mais voltada à qualidade do preenchimento deste espaço.

5) Observando a Fig. 8, as curvas de sharpness e loudness apresentam uma semelhança de comportamento. Ambas têm um início estável, parte B mais variável, e com uma média de valores um patamar acima da parte inicial. Na medida em que aproxima-se o fim desta parte, os valores do gráfico ascendem gradualmente até o valor máximo da peça ser atingido. A parte $\mathrm{A}^{\prime}$ inicia-se com valores médios do mesmo nível do começo da parte $\mathrm{B}$, porém no fim há uma curva decrescente, até ser atingido o mesmo patamar do início da peça. As transições entre as segmentações formais apresentam valores bastante baixos de intensidade sonora e aspereza, ambas em oposição à informação do centroide que, nestes trechos, nos mostra a concentração da percepção do brilho numa região bastante aguda.

Portanto, nesta peça percebe-se que na medida em que aumenta-se a quantidade de instrumentos que tocam juntos e a quantidade de ataques de notas (parte B), obviamente há um acréscimo na percepção da intensidade sonora (loudness). A percepção da aspereza (sharpness) também sofre um acréscimo 
justamente por ela ser parcialmente dependente da sensação de loudness, mas também pelo fato de neste trecho haver um acréscimo da presença de batimentos (roughness) na percepção do agregado tonal (principalmente nos compassos 26 a 29). Aqui, há um tutti orquestral, com a densidade de eventos bastante alta e harmonia bastante complexa. Nossa percepção separa este agregado em diferentes camadas, como madeiras e metais entoando notas na região médio-aguda (sons mais contínuos) e cordas realizando movimento descendente em tremolo em direção ao grave. 0 aumento dos batimentos decorre do grande cromatismo deste trecho, que produz harmônicos não coincidentes das notas tocadas, dificultando a ocorrência da fusão de timbres por meio desta semelhança.

6) Ampliando as afirmações do final do item anterior, conclui-se que, em Farben, a sensação de harmonicidade está relacionada com o grau de fusão de timbres. Trechos em que o gráfico de inarmonicidade (Fig. 12) se mantém relativamente constante são aqueles em que o timbre é percebido como mais homogêneo. Na medida em que temos alguma nota que se destaca perceptivamente das outras, por exemplo o Si 3 tocado pelo oboé (c. 15), a sensação de inarmonicidade aumenta. Na transição entre as partes, principalmente entre as partes B e A', a sensação de harmonicidade é bastante alta pois, perceptivamente, temos uma sonoridade bastante límpida e homogênea nestes trechos. Logo a seguir (c. 31), com a entrada do piccolo, harpa e celesta tocando notas bastante agudas em oitavas há uma clara separação de camadas. Este é outro fator que contribui para o aumento da sensação de inarmonicidade: o prolongamento do acorde límpido do compasso anterior em oposição a sons bastante agudos e estridentes. É o momento de maior inarmonicidade da peça.

Em relação à hipótese colocada na introdução do trabalho, em que a percepção dos parâmetros do som influenciaria o resultado da percepção do timbre, acreditamos que foi possível perceber a existência desta correlação a partir das análises apresentadas com os descritores de áudio. 0 centroide nos forneceu informações sobre a forma; o croma nos situou sobre a percepção das alturas; sharpness, 
inarmonicidade, e novamente o croma, nos forneceram dados sobre a percepção harmônica; loudness nos deu o panorama da percepção da intensidade, em relação à sonoridade geral. Em Farben, uma peça que apresenta um tempo liso - tal como a definição de Boulez (1963, p. 99-113) - pensamos que a duração pura de Bergson seja capaz de explicar nossa sensação de duração, uma duração psicológica formada pela fusão dos múltiplos estados de consciência, relacionados tanto com as sensações como com a memória.

Considerando as observações acima, concluímos também que a capacidade do nosso ouvido de fundir timbres é relativa. No caso de Farben, Schoenberg propõe sua melodia de timbres baseada num acorde tonal (Fig. 2). Na audição da peça, nosso ouvido detecta alterações e mudanças de densidade em relação à proposta inicial do compositor, que valoriza as partes sustentadas do espectro sonoro e retira as partes ruidosas do espectro que são geradas pelo ataque das notas. Neste caso a 322 fusão ocorre nas partes estacionárias do som e pode ser explicada pela existência de modulações pelo jitter, produzido pelo mecanismo dos próprios instrumentos.

\section{Referências bibliográficas}

BERGSON, Henri. Ensaio sobre os Dados Imediatos da Consciência. Trad. João da Silva Gama. Lisboa: Edições 70, 1988 [1889].

. Matéria e Memória. Trad. Paulo Neves. 4aㅡ. Ed. São Paulo: Martins Fontes, 2010 [1896].

BOULEZ, Pierre. Penser la musique aujourd'hui. Paris: Éditions Gonthier, 1963.

BURKHART, Charles. Schoenberg's Farben: An Analisys of Op. 16 n. 3. Perspectives of New Music, Seattle, v. 12, n. 1/2, p. 141-72, 1973-74.

CRAMER, Alfred. Schoenberg's Klangfarbenmelodie: A principle of early atonal music. Music Theory Spectrum, Berkeley, v. 24, n. 1, p. 134, 2002.

DAHLHAUS, Carl. Schoenberg and the New Music: Essays by Carl Dahlhaus. Trad. Derrick Puffett, Alfred Clayton. Cambridge: Cambridge University Press, 1989. 
DOFLEIN, Erich. Schönbergs Opus 16 Nr. 3 der Mythos der Klangfarbenmelodie. Melos Zeitschrift für neue Musik. Mainz, p. 203-5, 1969.

DUBNOV, Shlomo; TISHBY, Naftali; COHEN, Dalia. Polyspectra as Measures of Sound Texture and Timbre. Journal of New Music Research, v. 26, p. 277-314, 1997.

FASTL, Hugo; ZWICKER, Eberhard. Psychoacoustics: facts and models. 3르. Ed. Nova York: Springer, 2007.

FÖRTIG, Peter. Arnold Schönberg Über Klangfarbe: Analyse des Opus 16 Nr. 3. Melos Zeitschrift für neue Musik. Mainz, p. 206- 9, 1969.

GOETHE, Johann Wolfgang von. Theory of Colours. Trad. Charles Lock Eastlake. Londres: John Murray, 1840. Disponível em: http://books.google.com. Acesso em 05 Set. 2013.

HELMHOLTZ, Hermann von. On the sensations of the tone as a physiological basis for the theory of music. Trad. Alexander Ellis. Nova York: Dover, 1954 [1875].

Treatise on physiological optics vol. II: The sensations of vision. Nova York: The Optical Society of America, 1924 [1911].

LEÃO MAIA, Igor. Klangfarbenmelodie: Orquestração do Timbre. 139 p. Dissertação de Mestrado. Instituto de Artes, Unicamp, Campinas, 2013a.

. Uma análise da organização e fragmentação da orquestração de Farben de Arnold Schoenberg. In: Encontro Internacional de Teoria e Análise Musical, 3, 2013. Anais do 3ํㅡㄹ ETAM. São Paulo: ECA-USP, 2013b, p. 209-17.

McADAMS, Stephen. Spectral Fusion, Spectral Parsing and the Formation of Auditory Images. 344p. Tese de Doutorado. Center for Computer Research in Music and Acoustics, Stanford University, Stanford, 1984.

MEYER-EPPLER, Werner. Problemas estatísticos e psicológicos da música eletrônica. In: MENEZES, Flo. Música eletroacústica: História e estéticas. 2a Ed. São Paulo: Edusp, 2009 [1954], p. 73-9.

PARNCUTT, Richard. Harmony: A psychoacoustical approach. Nova York: Springer, 1989.

PEETERS, Geoffroy. A large set of audio features for sound description (similarity and classification) in the CUIDADO project. Paris: IRCAM, 2004. Disponível em: 
http://recherche.ircam.fr/anasyn/peeters/ARTICLES/Peeters_2003_c uidadoaudiofeatures.pdf. Acesso em 22 Ago. 2013

RUFER, Josef. Noch einmal Schönbergs Opus 16. Melos Zeitschrift für neue Musik. Mainz, p. 366 - 8, 1969.

SCHOENBERG, Arnold. Anton Webern: Klangfarbenmelodien [1951]. In: SCHOENBERG, Arnold. Style and Idea: Selected writings of Arnold Schoenberg. Berkeley: University of California Press, 1975. p. 484-5. 1917.

Die Gluckliche Hand Op. 18. Partitura. Viena: Universal Edition, $\overline{1922 .}$

Fünf Orchesterstücke Op. 16. Partitura. Leipzig: Edition Peters, Harmonia. Trad. Marden Maluf. São Paulo: Editora UNESP, 2001 [1913].

SCHOUTEN, Jan Frederik. The residue: A new component in Subjective sound analysis. Proceedings of the Koninklijke Nederlandse Akademie van Wetenschappen, 41, 1940, p. 1083-93.

SEEBECK, August. Beobachtungen über einige Bedingungen der Entstehung von Tönen. Annalen der Physik und Chemie, 53, 1841, p. 417-36. 449-81.

Ueber die Sirene. Annalen der Physik und Chemie, 60, 1843, p.

SHAWN, Allen. Arnold Schoenberg's Journey. Cambridge: Harvard University Press, 2003.

SHEPARD, Roger. Circularity in judgments of relative pitch. The journal of the acoustical society of America. Melville, v. 36, n. 2, p. 2346-53, 1964.

TERHARDT. Ernst. Pitch, consonance and harmony. The Journal of the Acoustic Society of America, v. 55, n. 5, p. 1061-9, 1974.

ZENDER, Hans. (Regente) Orquestra Sinfônica da Rádio de Saarbrüken. 5 ORCHESTERSTÜCKE OP. 16. SCHOENBERG, Arnold (Compositor). Compact Disc. CPO, 1997.

ZUBEN, Paulo. Ouvir o som. São Paulo: Ateliê Editorial, 2005. 